\title{
IGRT After Prostatectomy: Evaluation of Corrective Shifts and Toxicity Using Online Cone Beam CT vs. Weekly Port Films for Target Localization
}

\author{
H. B. Eldredge \\ Thomas Jefferson University and Hospitals \\ M. Studenski \\ Thomas Jefferson University and Hospitals \\ S. Keith \\ Thomas Jefferson University and Hospitals \\ E. J. Trabulsi \\ Thomas Jefferson University and Hospitals. \\ Follow this and additional works at: https://jdc.jefferson.edu/bodinejournal \\ Haryef the Oncology Commons \\ Themas Jefferson University and Hospitals to this document benefits you
}

\section{Reenextpage fradditional authors}

Eldredge, H. B.; Studenski, M.; Keith, S.; Trabulsi, E. J.; Harvey, A.; Lallas, C.; Gomella, L.; Dicker, A. P.; and Showalter, T. N. (2010) "IGRT After Prostatectomy: Evaluation of Corrective Shifts and Toxicity Using Online Cone Beam CT vs. Weekly Port Films for Target Localization," Bodine Journal: Vol. 3 : Iss. 1 , Article 29.

DOI: https://doi.org/10.29046/TBJ.003.1.028

Available at: https://jdc.jefferson.edu/bodinejournal/vol3/iss1/29

This Article is brought to you for free and open access by the Jefferson Digital Commons. The Jefferson Digital Commons is a service of Thomas Jefferson University's Center for Teaching and Learning (CTL). The Commons is a showcase for Jefferson books and journals, peer-reviewed scholarly publications, unique historical collections from the University archives, and teaching tools. The Jefferson Digital Commons allows researchers and interested readers anywhere in the world to learn about and keep up to date with Jefferson scholarship. This article has been accepted for inclusion in Bodine Journal by an authorized administrator of the Jefferson Digital Commons. For more information, please contact: JeffersonDigitalCommons@jefferson.edu. 
IGRT After Prostatectomy: Evaluation of Corrective Shifts and Toxicity Using Online Cone Beam CT vs. Weekly Port Films for Target Localization

\section{Authors}

H. B. Eldredge, M. Studenski, S. Keith, E. J. Trabulsi, A. Harvey, C. Lallas, L. Gomella, A. P. Dicker, and T. N. Showalter 


\section{IGRT After Prostatectomy: Evaluation of Corrective Shifts and Toxicity Using Online Cone Beam CT vs. Weekly Port Films for Target Localization}

Eldredge, H.B., ${ }^{1}$ Studenski, M., ${ }^{1}$ Keith, S., ${ }^{2}$ Trabulsi, E.J., ${ }^{3}$ Harvey, A.,, ${ }^{1}$ Lallas, C., ${ }^{3}$ Gomella, L., ${ }^{3}$ Dicker, A.P., ${ }^{1}$ Showalter. T.N. ${ }^{1}$

1 Department of Radiation Oncology,

2Department of Pharmacology and Experimental Therapeutics, Division of Biostatistics,

${ }^{3}$ Department of Urology,

Thomas Jefferson University and Hospitals, Philadelphia, PA

\section{Purpose/Objective(s)}

Image guidance (IG) may permit higher radiotherapy (RT) doses ( $>65 \mathrm{~Gy}$ ) after radical prostatectomy (RP) without increased toxicity, with improved accuracy and smaller margins. Conebeam (CBCT) allows IGRT with volumetric images. This study evaluated CBCT shifts and toxicity after conformal IGRT, compared to RT with port films.

\section{Materials/Methods}

After IRB approval, 68 consecutive patients who received post-RP RT (2005-2009) with CBCT were identified. Median dose was 68.4 Gy (R 66.6-70.2) delivered with 4-field, conformal IGRT. Online CBCT images were acquired 3-5 times weekly and were automatically co-registered to reference CT based on pelvic anatomy. Corrective shifts were made for deviations $\geq 5 \mathrm{~mm}$. A comparative group was comprised of 150 patients who received post-RP RT (1990-2004) to a median of 64.8 Gy (R 59.4-68.4) with weekly port films. Genitourinary (GU) and gastrointestinal (GI) toxicity (RTOG grade (G) $\geq 2$ ) was compared using Fisher's exact test and odds ratio (OR) computed by logistic regression adjusted for dose. Two-way interactions were also investigated.

\section{Results}

CBCT mean shifts (SD) for 1053 fractions were $2.8 \mathrm{~mm}$ (2.8), $2.0 \mathrm{~mm}$ (2.4) \& $3.1 \mathrm{~mm}$ (2.9) in the left-right (LR), anterior-posterior (AP) \& superior-inferior (SI) axes, respectively. Shifts $\geq 5 \mathrm{~mm}$ were required for $15 \%, 6 \% \& 19 \%$ of fractions in the LR, AP \& SI axes, respectively. Late toxicity was evaluable in 43 patients (median follow-up 15 mo., R 3-46) in the CBCT group and 135 (median 74 mo., R 3-168) in the control group. GU and GI toxicity was largely G0-1. No G4 toxicity was reported. G2 \& G3 acute GU toxicity was experienced by $13 \%$ $(n=9) \& 2 \%(n=1)$ of patients in the CBCT group, respectively, while $13 \%(n=19)$ had G2 acute GU toxicity in the control group. G2 late GU toxicity was experienced by $7 \%(n=3)$ of patients in the CBCT group and $5 \%(n=7)$ in the control group. G2 acute GI toxicity was experienced by $13 \%(n=9)$ in the CBCT group and $15 \%(n=23)$ of controls. Late GI toxicity was G2 \& G3 in $2 \%(n=1)$ \& $2 \%(n=1)$ of patients in the CBCT group, respectively, while $1 \%(n=1)$ had G2 toxicity in the control group. Acute GU (Fisher $\mathrm{p}=0.67$ ) and GI $(\mathrm{p}=0.84)$ toxicity was not significantly different between the two groups. There was no association between acute GI toxicity and CBCT $(\mathrm{p}=0.74)$. Increased odds of acute GU toxicity were observed for doses $>68.4$ Gy (interaction $p=0.02$ ), which were only delivered in the IGRT group.

\section{Conclusion}

Rates of acute toxicity with CBCT-guided post-RP RT to $68.4 \mathrm{~Gy}$ were similar to treatment to 64.8 Gy without IGRT. The higher rate of acute GU toxicity with doses $>68.4$ Gy suggests a potential role for IMRT. IGRT with CBCT is associated with mostly G0-1 toxicity and minimal grade $\geq 2$, suggesting that CBCT is a safe IG strategy. Longer follow-up is desired to compare late toxicity. 